\title{
p53 accumulation due to down-regulation of ubiquitin: relevance for neuronal apoptosis
}

\author{
Z Tan ${ }^{1}$, W Qu ${ }^{2}$, W Tu' ${ }^{1}$, W Liu ${ }^{4}$, M Baudry ${ }^{4}$ and \\ SS Schreiber*,1,3 \\ 1 Department of Neurology, University of Southern California Keck School of \\ Medicine, Los Angeles, California, CA 90033, USA \\ 2 Department of Occupational Science and Therapy, University of Southern \\ California Keck School of Medicine, Los Angeles, California, CA 90033, USA \\ ${ }^{3}$ Department of Cell and Neurobiology, University of Southern California Keck \\ School of Medicine, Los Angeles, California, CA 90033, USA \\ ${ }^{4}$ Program in Neuroscience, University of Southern California, Los Angeles, \\ California, CA 90089-2520, USA \\ * Corresponding author: SS Schreiber, Department of Neurology, University of \\ Southern California Keck School of Medicine, 1333 San Pablo St. MCH 142, \\ Los Angeles, California, CA 90033, USA. Tel: 323-442-1057; Fax: 323-442- \\ 1056; E-mail: sschreib@hsc.usc.edu
}

Received 2.2.00; accepted 7.3.00

Edited by JC Reed

\begin{abstract}
The p53 tumor suppressor protein is a major regulator of cell growth arrest and apoptosis in response to DNA damage. Both p53 function and stability are tightly controlled by Mdm2, which binds to the p53 N-terminus and targets p53 for ubiquitin-mediated proteolysis. Previous studies suggest that adrenalectomy-induced neuronal apoptosis is p53-dependent. Here we demonstrate both nuclear accumulation and functional activation of p53 protein in apoptotic hippocampal neurons from adrenalectomized rats. Increased p53 expression occurred despite the accumulation of its negative regulator, Mdm2, and the formation of p53-Mdm2 complexes. The persistence of $p 53$ expression was explained by a striking decrease in free ubiquitin in p53-positive neurons. The addition of exogenous ubiquitin to p53-Mdm2 complexes from apoptotic neurons restored p53 degradation. These findings demonstrate a novel mechanism of p53 stabilization mediated by decreased ubiquitin levels. Regulation of free ubiquitin may therefore be an effective way to modulate p53dependent apoptosis in certain cell types. Cell Death and Differentiation (2000) 7, 675-681.
\end{abstract}

Keywords: p53; ubiquitin; Mdm2; neuronal; apoptosis

Abbreviations: ADX, adrenalectomy; CNS, central nervous system; DG, dentate gyrus; $P C$, pyramidal cell

\section{Introduction}

The p53 tumor suppressor protein is a major regulator of cell growth arrest and apoptosis in response to DNA damage and other cellular stressors. ${ }^{1-3}$ In addition to post-translational modifications p53 function is tightly controlled by protein-protein interactions. ${ }^{1,2}$ In this regard, the Mdm2 oncoprotein, a product of a p53-responsive gene, is a major inhibitor of p53 function and abundance. ${ }^{4,5} \mathrm{Mdm} 2$ binds to the $\mathrm{N}$-terminal transcriptional activation domain of p53 protein and blocks p53-regulated gene expression. ${ }^{4,5}$ Importantly, Mdm2 also has ubiquitin ligase activity, and through ubiquitination targets p53 for proteasome-mediated degradation. ${ }^{6,7}$ Thus, Mdm2 plays a key role in an autoregulatory feedback loop that maintains low p53 levels in normal cells and limits the magnitude of the p53 response following DNA damage. ${ }^{6-9}$

Bilateral adrenalectomy (ADX) in adult rats results in the cumulative loss of dentate gyrus granule neurons of the hippocampus through an apoptotic pathway (Figure 1a, inset). ${ }^{10,11}$ Recent evidence suggests that neuronal apoptosis may be triggered by abnormal activation of the cell cycle. ${ }^{12,13}$ In this regard, we previously demonstrated both DNA fragmentation and p53 induction in apoptotic hippocampal granule cells following ADX. ${ }^{14}$ Additional evidence supporting a causal relationship between p53 activation and neuronal apoptosis comes from studies demonstrating that p53 overexpression results in apoptosis of hippocampal neurons in culture, while granule cells from p53-deficient mice are protected against ADX-induced death. ${ }^{15-17}$ Thus activation of the p53-DNA damage response pathway may play a central role in certain types of neuronal degeneration.

Although a regulatory relationship between p53 and Mdm2 has been well-documented outside the central nervous system (CNS), i.e., Mdm2 inhibits p53 activity and promotes p53 degradation, there is a profound lack of information regarding p53-Mdm2 interactions in the CNS. Here we demonstrate the unexpected finding of increased Mdm2 levels in p53-positive neurons undergoing apoptosis. Further investigation of the p53 proteolytic pathway revealed that apoptotic neurons exhibited a marked decrease in ubiquitin expression. Following addition of exogenous ubiquitin to p53-Mdm2 complexes isolated from adrenalectomized rats there was almost complete restoration of p53 degradation. These findings demonstrate a novel mechanism of p53 stabilization that is mediated by decreased levels of free ubiquitin. Thus down-regulation of ubiquitin expression may play a major role in the p53 response to DNA damage and apoptosis in certain cell types.

\section{Results}

ADX-induced neuronal apoptosis is associated with increased expression and nuclear translocation of $\mathrm{p} 53$ protein

Since p53 mRNA is induced in apoptotic granule neurons following $A D X,{ }^{14}$ we determined whether there is a 

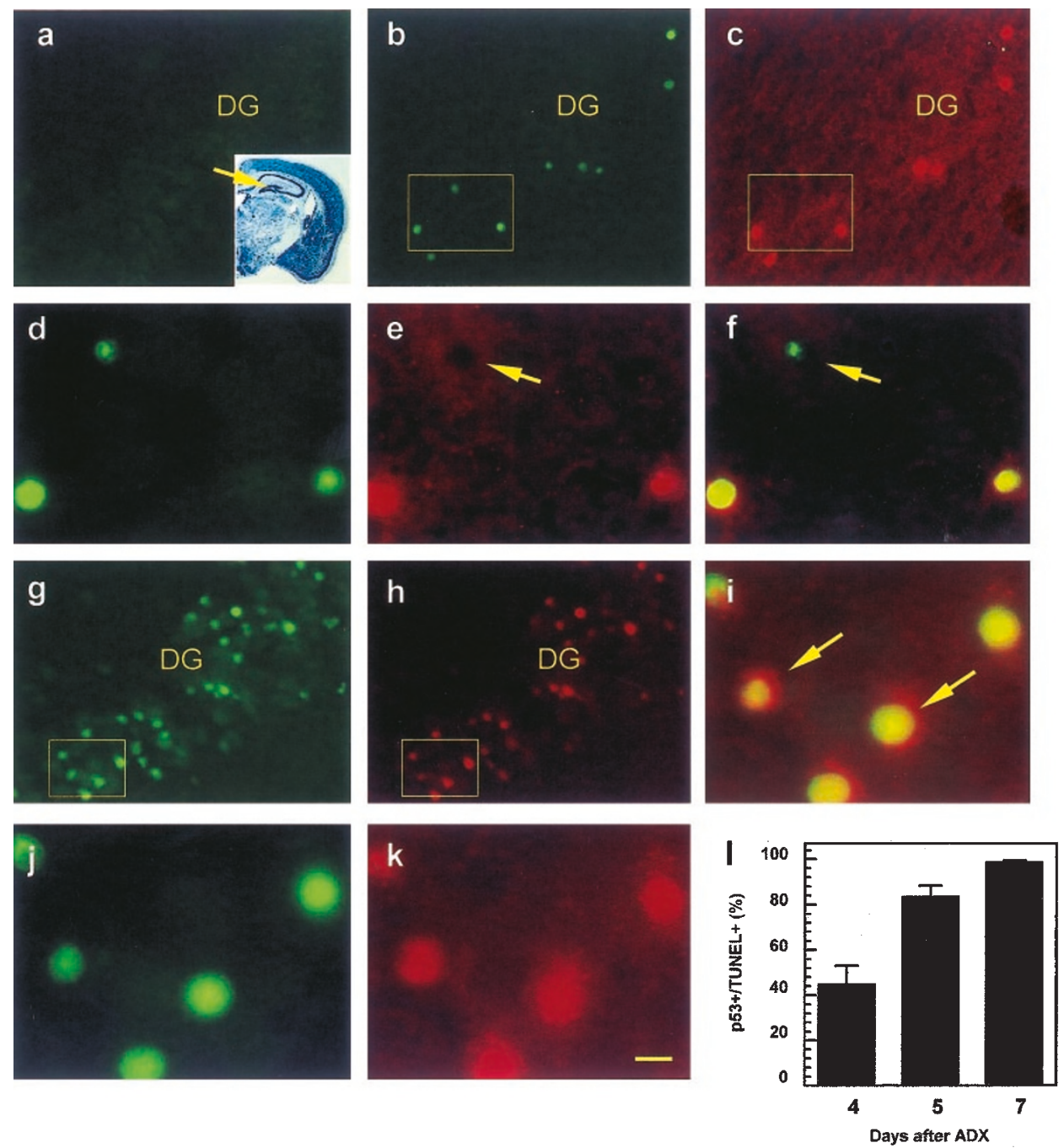

Figure 1 p53 and DNA damage are co-localized in apoptotic granule cells after ADX. Dual immunofluorescence labeling for both p53 (red) and TUNEL (green) was performed as described in Materials and Methods. (a) Section from a sham-operated rat shows no TUNEL-positive cells in the dentate gyrus granule cell layer (DG). Similar results were obtained for p53 (see Figure 3a). Inset, coronal hemisection through the hippocampus of an adult rat brain; arrow denotes the dentate gyrus granule cell layer (modified from www.nervenet.org/mbl). (b) Distribution of TUNEL-positive granule cells in the dentate gyrus 5 days after ADX. (c) The same section stained with anti-p53 antibody. Areas highlighted in (b) and (c) are shown at higher magnification in (d) and (e), respectively. Arrow in (e) denotes a p53negative cell. (f) Overlap of (d) and (e) shows that p53 and DNA damage co-localize in most cells (yellow). Some p53-negative cells are TUNEL-positive (arrow). (g) Distribution of TUNEL-positive granule cells in the dentate gyrus 7 days after ADX. (h) The same section stained with anti-p53 antibody. Areas highlighted in (g) and (h) are shown at higher magnification in (j) and (k), respectively. (i) Overlap of (j) and (k) shows co-localization of p53 and DNA damage (arrows). (I) The number of p53- and TUNEL-positive cells were counted (four rats per time point, three sections per rat), and the ratio [p53+/TUNEL+] plotted as a function of time after ADX. Data are depicted as mean \pm S.D. Scale bar: $\mathbf{a}-\mathbf{c}, \mathbf{g}, \mathbf{h}: 80 \mu \mathrm{m} ; \mathbf{d}-\mathbf{f}, \mathbf{i}-\mathbf{k}: 16 \mu \mathrm{m}$

corresponding change in $\mathrm{p} 53$ protein. Activated p53 protein typically undergoes translocation to the nucleus where it functions as a transcription factor. ${ }^{1-3}$ Immunohistochemistry revealed low levels of cytoplasmic p53 in granule cells from sham-operated control rats (Figure 1a). By contrast, following ADX there was a cumulative increase in nuclear p53-immunoreactivity as well as DNA damage that was detected by TUNEL (Figure $1 b-k$ ). The ADX-induced alteration in p53 expression was confirmed by Western blotting (Figure 3o, lanes 1, 2). In addition, dual immunofluorescence revealed that there was complete overlap between the distributions of TUNEL- and p53positive cells at 7 days after ADX (Figure 1f,i). At 4 and 5 days after ADX a subpopulation of TUNEL-positive cells was observed to be p53-negative (Figure 1d,e,l).

\section{ADX activates endogenous neuronal p53 protein}

To further evaluate the mechanism of $\mathrm{p} 53$-mediated neuronal apoptosis we investigated p53 sequence-specific DNA binding activity in granule cell nuclear extracts from adrenalectomized rats. A significant increase in DNA binding activity was detected by 5 days (Figure 2a) consistent with the induction of p53 mRNA and protein expression. These findings were supported by an RT-PCR analysis revealing increased expression of Mdm2, a transcriptional target of p53 (Figure 2b). 
a

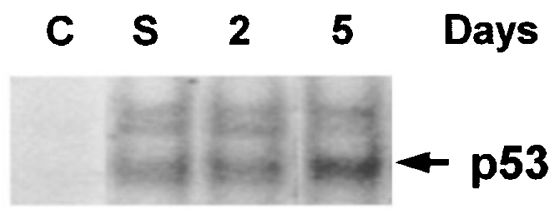

b

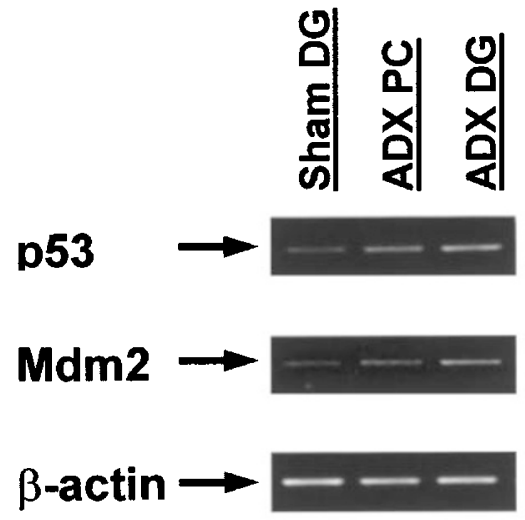

Figure 2 Effects of ADX on p53 DNA binding activity and transcriptional activation. (a) EMSA was performed as described using granule cell extracts prepared from either sham-operated rats (S) or at specified times after ADX. C oligonucleotide probe only. (b) Total RNA from the dissected dentate gyrus (DG) or the adjacent pyramidal cell (PC) layer of either sham-operated or adrenalectomized rats, was analyzed semi-quantitatively by RT-PCR as described. An increase in amplified products from ADX PC is due to incomplete dissection

\section{Mdm2 is upregulated and interacts with p53 after ADX}

Although Mdm2 has been clearly shown to regulate p53 expression and activity in non-neural cells, ${ }^{6-9}$ the functional importance of p53-Mdm2 interactions in the CNS has not been explored. We therefore sought to determine the relationship between $\mathrm{p} 53$ and Mdm2 in vivo following ADX. Increased expression of p53 and Mdm2 mRNA and protein was observed in apoptotic granule neurons (Figures $2 b$ and $3 o, p$ ), and co-localization (Figure $3 c-j$ ) implied that there was a significant physical interaction. This was confirmed by the isolation of p53-Mdm2 complexes from granule cell lysates prepared from adrenalectomized rats (Figure 3o, lanes 3, 4).

\section{p53 accumulation in apoptotic neurons is associated with downregulation of ubiquitin}

The presence of p53-Mdm2 complexes in granule cell extracts indicated that Mdm2 binding was functionally intact, and suggested that other alterations in the p53-Mdm2 proteolytic pathway were responsible for stabilizing p53. As Mdm2 regulates p53 degradation through its ubiquitin ligase activity, ${ }^{18}$ we investigated the possibility that modulation of ubiquitin levels played a role in regulating p53 abundance following ADX. Notably, there was a striking decrease in ubiquitin immunoreactivity only in p53-positive neurons, while adjacent p53-negative neurons exhibited abundant amounts of ubiquitin (Figure 4c,d,f,g). This result was confirmed by Western blot analysis of free ubiquitin levels in granule cell lysates (Figure 4i).

\section{Exogenous ubiquitin restores the p53 degradation pathway}

Although ubiquitin levels were decreased it was important to determine whether activation of ubiquitin-mediated proteolysis was still possible. Initial studies using ubiquitin-depleted granule cell extracts from naïve rats demonstrated that p53 degradation could be reconstituted by adding exogenous ubiquitin (Figure 4j, lanes 1, 2). Similarly, p53 degradation was enhanced following the addition of exogenous ubiquitin to p53-Mdm2 complexes isolated from the hippocampi of adrenalectomized rats (Figure $4 \mathrm{j}$, lanes 3,4 ).

\section{Discussion}

Among the multiple mechanisms regulating p53 function protein-protein interactions play a dominant role. ${ }^{1,2}$ In this regard, the Mdm2 protein, encoded by a p53-target gene, is a critical regulator of $\mathrm{p} 53$ activity in a variety of cell types. ${ }^{4,5}$ Previous studies have shown that Mdm2 binds to and blocks the N-terminal transactivation domain of p53, and also promotes the rapid degradation of p53 through a ubiquitindependent pathway. ${ }^{6-9}$ Evidence for the functional importance of Mdm2 binding is also provided by reports demonstrating that overexpression of Mdm2 blocks both p53-mediated cell cycle arrest and apoptosis in cultured cells. ${ }^{19-21}$ Interestingly, inhibition of p53 degradation by proteasome inhibitors, which act downstream from Mdm2, enhances both p53 accumulation and apoptosis. ${ }^{22}$

The results of our study extend those obtained in cultured cells by demonstrating a significant accumulation of endogenous p53 in the nuclei of apoptotic neurons in vivo. While p53 immunoreactivity and TUNEL staining were typically co-localized, the presence of p53-negative cells containing fragmented DNA at the earliest time point studied is consistent with the idea that DNA damage precedes and triggers p53 activation. The increase in p53 DNA binding activity and Mdm2 gene transcription indicate that p53 is functionally active in apoptotic neurons. As DNA damage, increased p53 expression and DNA binding also occur during excitotoxic cell death, ${ }^{23,24}$ activation of the p53 pathway may be a common response of mature CNS neurons exposed to DNA-damaging, apoptotic stimuli.

Until now there have been no investigations into the relationship between p53 and Mdm2 in the CNS. In the present study, increased expression and co-localization of both p53 and Mdm2, as well as formation of p53-Mdm2 complexes were observed in apoptotic neurons. Although differences between the relative amounts of free versus bound p53 were not investigated, our findings suggest that there was an initial activation of the p53-Mdm2 autoregulatory loop following ADX. However, the persistently elevated p53 levels in the presence of increased Mdm2 expression suggested that there was an impairment of 


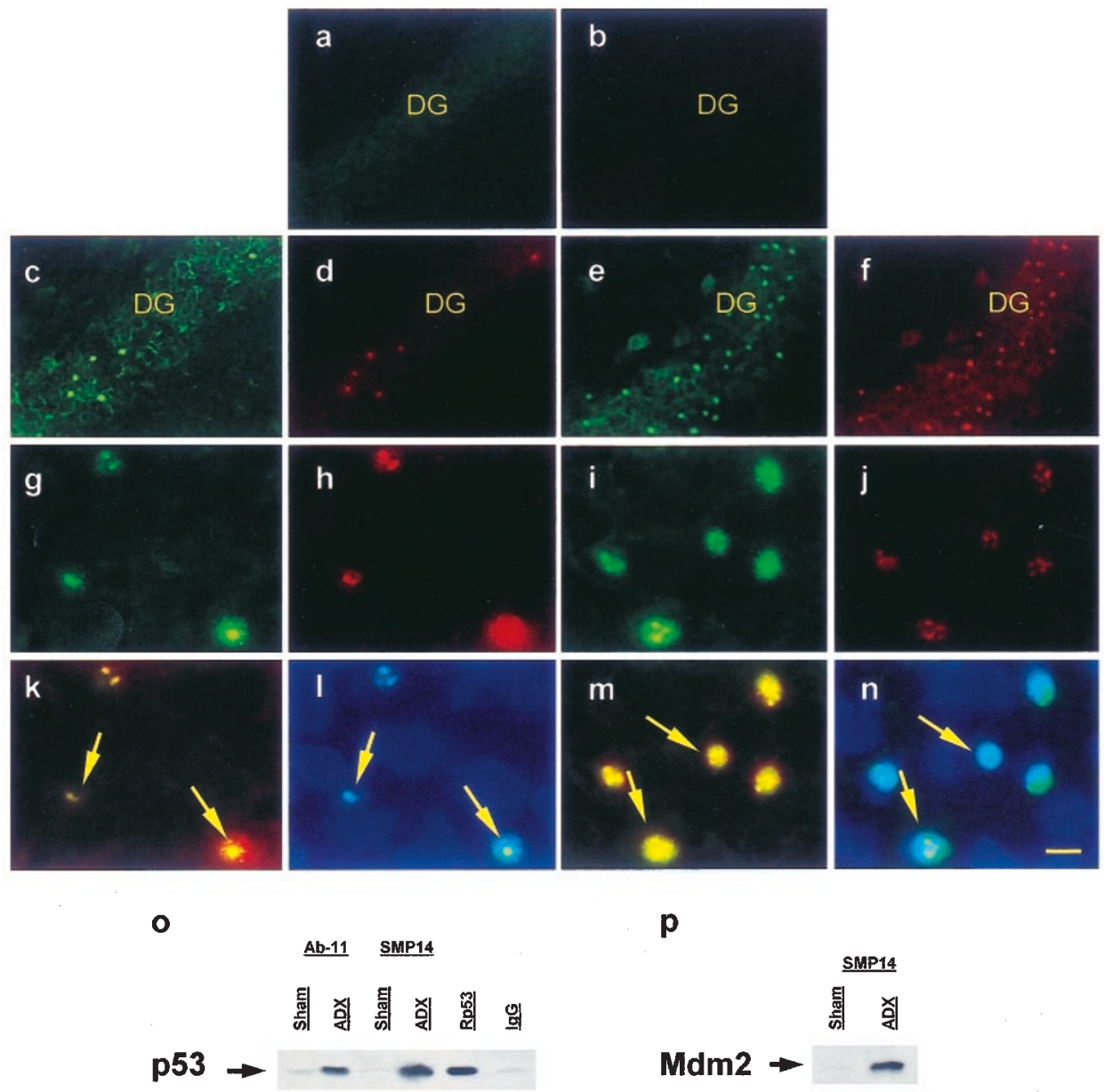

Figure 3 Expression and co-localization of p53 and Mdm2, and formation of p53-Mdm2 complexes after ADX. Dual immunofluorescence labeling for both p53 (green) and Mdm2 (red) was performed as described in Materials and Methods. (a) Section from a sham-operated rat stained with anti-p53 antibody. (b) The same section stained with anti-Mdm2 antibody. (c) Distribution of p53-positive cells 5 days after ADX. (d) The same section stained with anti-Mdm2 antibody. (e) Distribution of p53-positive cells 7 days after ADX. (f) The same section stained with anti-Mdm2 antibody. DG, dentate gyrus. (g) to (j) Higher power views of cells in $(\mathbf{c}-\mathbf{f})$, respectively. (k) and $(\mathbf{m})$ Overlap reveals co-localization (yellow) of p53 and Mdm2 in cells at 5 and 7 days post-ADX, respectively (arrows). (I and $\mathbf{n}$ ) p53 also co-localizes with the nuclear marker, DAPI, in the same sections (arrows). (o) Granule cell lysates were prepared from either sham or adrenalectomized rats, immunoprecipitated using either a p53-specific (Ab-11) or anti-Mdm2 (SMP14) antibody, and p53 detected using the anti-p53 antibody, CM5. Rp53, recombinant p53 standard; IgG, heavy chain immunoglobulin used in immunoprecipitation. (p) Immunoprecipitation of Mdm2 in granule cell lysates from sham and ADX groups. Equal amounts of lysates were used in first 2 lanes of (o) and (p). Scale bar: $\mathbf{a}-\mathbf{f}: 100 \mu \mathrm{m} ; \mathbf{g}-\mathbf{n}: 16 \mu \mathrm{m}$

either Mdm2 function or p53 degradation downstream from Mdm2 binding. Co-localization studies demonstrated reduced levels of ubiquitin in p53-positive neurons providing strong evidence for a novel mechanism of p53 stabilization. Since the ubiquitin ligase function of Mdm2 was preserved as demonstrated by reconstitution experiments, we conclude that the accumulation of p53 protein was due to a marked decrease in free ubiquitin.

Ubiquitin has long been recognized to play a central role in protein degradation under various physiological conditions, and has also been implicated in malignant transformation and other pathological states. ${ }^{25}$ Abnormal aggregates containing ubiquitinated proteins are commonly observed in neurodegenerative diseases. ${ }^{26}$ By contrast, the functional significance of decreased ubiquitin levels is unknown. Previous studies have demonstrated down- regulation of ubiquitin in vulnerable CA1 pyramidal neurons following transient cerebral ischemia. ${ }^{27-29}$ Notably, the distribution of cells with low levels of ubiquitin closely matched that of ischemia-induced neuronal degeneration. Increased p53 expression has been recently demonstrated following transient cerebral ischemia. ${ }^{30}$ Combined with our results, these findings suggest a link between decreased ubiquitin, p53 accumulation and ischemic cell death. Outside the CNS, low levels of free ubiquitin may contribute to the sustained p53 response reported to occur in human fibroblasts following DNA damage, as well as the accumulation of p53 protein in certain tumor cell lines expressing increased amounts of Mdm2. $31-33$

In conclusion, our results suggest that ubiquitin may be a key determinant of p53 stabilization and apoptotic cell 

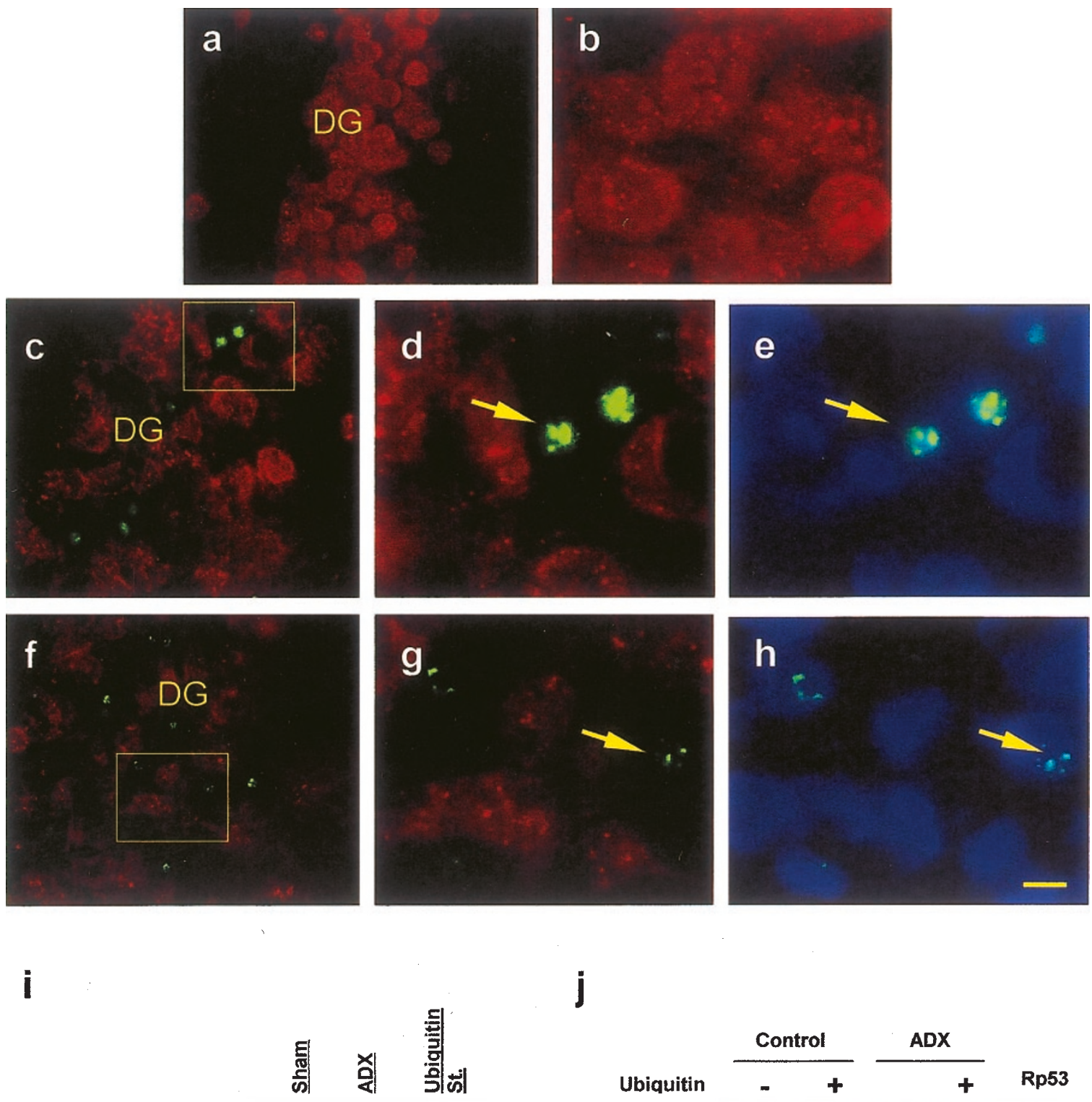

Ubiquitin

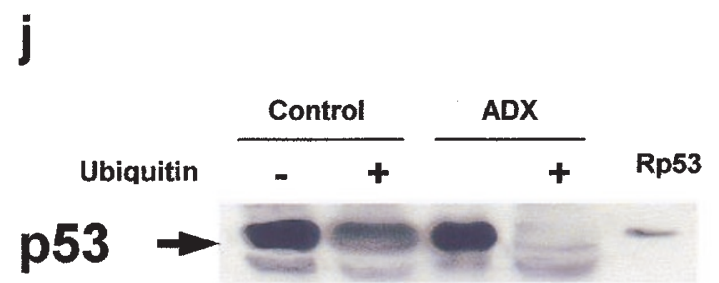

Figure 4 Decreased ubiquitin expression is associated with p53 stabilization in apoptotic granule cells. Dual immunofluorescence labeling for both p53 (green) and ubiquitin (red) was performed as described in Materials and Methods. (a) Section from a sham-operated rat stained with anti-p53 and anti-ubiquitin antibodies DG, dentate gyrus. (b) Higher power view of cells in (a). (c) p53-positive cells exhibit reduced ubiquitin immunoreactivity 5 days after ADX. (d) p53-positive cells in (c) are shown at higher magnification (arrow). (e) Nuclear p53 co-localizes with DAPI in these cells (arrow). (f) At 7 days post-ADX, p53-positive cells also have decreased ubiquitin. (g) A p53-positive cell is shown at higher magnification and (h) is also DAPI-positive (arrows). (i) Western blot analysis of granule cell extracts from sham or adrenalectomized rats using anti-ubiquitin antibody. Ubiquitin st., ubiquitin standard. (j) p53-Mdm2 complexes from adrenalectomized rats were immunoprecipitated and incubated with either ubiquitin-depleted lysates from naive rats or granule cell extracts from adrenalectomized rats, with or without exogenous ubiquitin. Rp53, recombinant p53 standard. Scale bar: a: $80 \mu \mathrm{m} ; \mathbf{c}, \mathbf{f}: 60 \mu \mathrm{m} ; \mathbf{b}, \mathbf{d}, \mathbf{e}, \mathbf{g}, \mathbf{h}: 16 \mu \mathrm{m}$

death in the CNS and perhaps other organ systems. Additional investigations are necessary to establish a clear role for ubiquitin and its related proteolytic cascade in neuronal apoptosis, as well as whether modulation of ubiquitin abundance can be an effective way to regulate p53-mediated apoptosis in the CNS.

\section{Materials and Methods}

\section{Animal surgery and tissue preparation}

All of the rats used in this study were treated in accordance with guidelines issued by the National Institutes of Health and Institutional Animal Care and Use Committee of the University of Southern 
California. Adult male Fisher 344 rats were adrenalectomized or shamoperated under pentobarbital anesthesia. ${ }^{14}$ At either 4,5 or 7 days after ADX rats were decapitated under methoxyfluorane anesthesia and half the brain rapidly frozen for cryostat sectioning at $10 \mu \mathrm{m}(n=4$ rats per time point). The dentate gyrus was dissected from the other half-brain and stored at $-80^{\circ} \mathrm{C}$. Serum corticosterone was nondetectable in cardiac blood samples from adrenalectomized rats; the average corticosterone level in sham-operated rats was $629 \pm 130 \mathrm{ng} /$ $\mathrm{ml}^{14}$

\section{Immunohistochemistry}

Frozen coronal brain sections from both adrenalectomized and shamoperated rats were fixed in $95 \%$ methanol for $1 \mathrm{~h}$, followed by microwave antigen retrieval in $10 \mathrm{mM}$ citrate buffer $(\mathrm{pH} 6.4)$ and incubation in a blocking buffer developed in our laboratory for $30 \mathrm{~min}$ at room temperature. Sections were incubated with a rabbit polyclonal anti-p53 antibody (CM5, Novocastra, Newcastle upon Tyne, UK) overnight at $4^{\circ} \mathrm{C}$, followed by several brief washes with phosphatebuffered saline (PBS), and either a biotinylated (see below) or FITCconjugated secondary antibody for $30 \mathrm{~min}$. For double-labeling, sections were incubated with $\mathrm{CM} 5$ and either a mouse monoclonal anti-Mdm2 (SMP14, Santa Cruz Biotechnology, Santa Cruz, CA, USA) or mouse monoclonal anti-ubiquitin (Ubi-1, Zymed Laboratories, San Francisco, CA, USA) antibody overnight at $4{ }^{\circ} \mathrm{C}$, followed by incubation with FITC-conjugated sheep anti-rabbit and Texas Red-conjugated goat anti-mouse secondary antibodies for $30 \mathrm{~min}$. After several PBS washes, sections were coverslipped with Vectorshield mounting medium containing DAPI (Vector Laboratories, Burlingame, CA USA) and analyzed by fluorescence microscopy.

\section{TdT-mediated dUTP nick end labeling (TUNEL)}

Frozen sections were fixed and microwaved as described above, labeled with an In Situ Cell Death Detection kit (Boehringer Mannheim, Indianapolis, IN, USA) according to the manufacturer's protocol, and analyzed by fluorescence microscopy. For double-labeling sections were re-microwaved after TUNEL staining, incubated in blocking buffer for 30 min at room temperature, washed in PBS and incubated with CM5 followed by a biotinylated secondary antibody. After several PBS washes, p53 immunoreactivity was detected using streptavidinconjugated Texas Red (Amersham, Piscataway, NJ, USA).

\section{Electrophoretic gel mobility shift assay (EMSA)}

Nuclear protein extracts were prepared from the dissected dentate gyrus of adrenalectomized and sham-operated rats as previously described. ${ }^{24} \mathrm{~A}$ double-stranded oligonucleotide coding for the p53 consensus sequence, 5'-TACAGAACATGTCTAAGCATGCTGG-3', was end-labeled with ${ }^{32} \mathrm{P}$-ATP and incubated with $10 \mu \mathrm{g}$ nuclear proteins in binding buffer. DNA-protein complexes were resolved by non-denaturing polyacrylamide gel electrophoresis. ${ }^{24}$

\section{Reverse transcription-polymerase chain reaction (RT-PCR)}

Total RNA was extracted from the dissected dentate gyrus 5 days after ADX using TRIZOL (Gibco BRL, Gaithersburg, MD, USA), and $1.5 \mu \mathrm{g}$ total RNA was reverse transcribed with $1 \mu \mathrm{g}$ oligo(dT) in $20 \mu \mathrm{l}$ of reaction buffer [ $1 \mathrm{mM}$ each dNTPs, $25 \mathrm{mM}$ Tris- $\mathrm{HCl}(\mathrm{pH} 8.3), 25 \mathrm{mM}$ $\mathrm{KCl}, 5 \mathrm{mM} \mathrm{MgCl}$, $5 \mathrm{mM}$ dithiothreitol, $0.25 \mathrm{mM}$ spermidine, $10 \mathrm{U}$ RNAse inhibitor (Boehringer Mannheim, Indianapolis, IN, USA), $10 \mathrm{U}$ avian myeloblastosis virus reverse transcriptase (Promega, Madison, WI, USA)] for $1 \mathrm{~h}$ at $42^{\circ} \mathrm{C}$ and $10 \mathrm{~min}$ at $75^{\circ} \mathrm{C}$. The reaction was stopped by addition of $100 \mu$ l of $10 \mathrm{mM}$ Tris- $\mathrm{HCl}(\mathrm{pH} \mathrm{7.4)}$ and $1 \mathrm{mM}$ EDTA. PCR was performed with $10 \mu \mathrm{l}$ of RT reaction mixture with $50 \mathrm{mM} \mathrm{KCl}, 10 \mathrm{mM}$ Tris-Cl (pH 9.0), 0.1\% Triton X-100, $1 \mathrm{mM} \mathrm{MgCl}_{2}$, $400 \mathrm{nM}$ each primer, $200 \mu \mathrm{M}$ each dNTP, $5 \mathrm{U}$ Taq DNA polymerase (Promega) in a final volume of $50 \mu \mathrm{l}$. The sample was subjected to 30 cycles $\left(94^{\circ} \mathrm{C}, 1 \mathrm{~min} ; 52^{\circ} \mathrm{C}, 1 \mathrm{~min} ; 72^{\circ} \mathrm{C}, 1 \mathrm{~min}\right)$ in a DNA Thermal Cycler (Perkin Elmer, Norwalk, CT, USA). Rat primer sequences: p53 antisense, 5'-GACTTCTTGTAGATGGCCATGG-3'; p53 sense, 5'ATGGAGGAGTCACAGTCGGATA-3'; Mdm2 antisense, 5'TTATCGTCTGGAAGCCAG-3'; Mdm2 sense, 5'-TGCAAGCACCTCACAGAT-3'. PCR using primers for rat $\beta$-actin (Promega) was performed simultaneously and the results were used to normalize cDNA amounts.

\section{Immunoprecipitation and Western blotting}

Dissected dentate gyri were sonicated in lysis buffer containing $50 \mathrm{mM}$ Tris- $\mathrm{HCl}$ (pH 7.5), $5 \mathrm{mM}$ EDTA, $150 \mathrm{mM} \mathrm{NaCl}, 0.5 \%$ NP-40 plus $1 \mathrm{mM}$ phenylmethylsulfonylfluoride and $1 \mu \mathrm{g} / \mathrm{ml}$ leupeptin. For immunoprecipitation $400 \mu \mathrm{g}$ total protein was incubated with either a p53-specific antibody (CM5 or Ab-11) or SMP14 conjugated to protein $A / G$ agarose beads (Santa Cruz) for $4 \mathrm{~h}$ at $4^{\circ} \mathrm{C}$ with gentle mixing. The pellets were washed in lysis buffer, resuspended and resolved on a denaturing polyacrylamide gel containing SDS and transferred to a nitrocellulose membrane overnight at $4{ }^{\circ} \mathrm{C}$. Membranes were incubated for $45 \mathrm{~min}$ at room temperature in Tris blocking buffer containing $8 \%$ nonfat dry milk and $0.1 \%$ Tween 20 . Proteins were detected by incubation with primary antibody for $2 \mathrm{~h}$ followed by a horseradish peroxidaseconjugated secondary antibody for $30 \mathrm{~min}$ and visualization by $\mathrm{ECL}$ (Amersham). For ubiquitin Western blotting $100 \mu \mathrm{g}$ total protein was loaded per lane and confirmed by Coomassie blue staining. The Ab-11 antibody was obtained from Calbiochem (San Diego, CA, USA).

\section{p53 degradation assay}

Employing a modification of the method described by Shkedy et al, ${ }^{34}$ granule cell lysates were prepared from the hippocampi of either naïve rats or at 7 days after ADX by successive freezing and thawing, and supernatants were frozen in ice-cold distilled water at $-80^{\circ} \mathrm{C}$. For ubiquitin depletion, $20 \mu \mathrm{l} \mathrm{Ubi-1} \mathrm{was} \mathrm{added} \mathrm{to} \mathrm{protein} \mathrm{lysates}(500 \mu \mathrm{g})$ from naïve rats and gently mixed for $3 \mathrm{~h}$ at $4{ }^{\circ} \mathrm{C}$, followed by addition of $50 \mu$ protein A/G agarose beads (Santa Cruz) and mixing for an additional $4 \mathrm{~h}$. After centrifugation the supernatant was stored at $-80^{\circ} \mathrm{C}$. Lysates were incubated with immunoprecipitated p53-Mdm2 complexes from adrenalectomized rats in a buffer $(25 \mathrm{mM}$ Tris- $\mathrm{HCl}$ (pH 7.5), $50 \mathrm{mM} \mathrm{NaCl}, 10 \mathrm{mM} \mathrm{MgCl}_{2}, 10 \mathrm{mM}$ DTT, $10 \mathrm{mM} \mathrm{ATP)} \mathrm{for}$ $1 \mathrm{~h}$ at $30^{\circ} \mathrm{C}$, with or without the addition of $6 \mu \mathrm{g}$ ubiquitin (Sigma). Following addition of sample buffer immunoprecipitates were electrophoretically separated and evaluated by Western blotting.

\section{Acknowledgements}

This work was supported by the NIH NS01337 and Sankyo Co., Ltd. (Tokyo). We thank Dr. Anna Taylor and Delia Tio for performing serum corticosterone measurements, Drs. Lucio Comai and Carol Miller for critically reviewing the manuscript, Dr. D-Y Wu for assistance with graphics and Dr. W Zhai for additional technical advice. 


\section{References}

1. Prives $C$ and Hall PA (1999) The p53 pathway. J. Pathol. 187: 112-126

2. Levine AJ (1997) p53, the cellular gatekeeper for growth and division. Cell 88 : $323-331$

3. Bennett MR (1999) Mechanisms of p53-induced apoptosis. Biochem. Pharmacol. 58: 1089-1095

4. Lozano G and Montes de Oca Luna R (1998) MDM2 function. Biochim. Biophys. Acta. 1377: M55-M59

5. Freedman DA and Levine AJ (1999) Regulation of the $p 53$ protein by the MDM2 oncoprotein - Thirty-eighth G.H.A. Clowes Memorial Award Lecture. Cancer Res. 59: 1-7

6. Maki CG, Huibregtse JM and Howley PM (1996) In vivo ubiquitination and proteasome-mediated degradation of p53. Cancer Res. 56: 2649-2654

7. Fuchs SY, Adler V, Buschmann T, Wu X and Ronai Z (1998) Mdm2 association with p53 targets its ubiquitination. Oncogene 17: 2543-2547

8. Haupt Y, Maya R, Kazak A and Oren M (1997) Mdm2 promotes the rapid degradation of p53. Nature 387: 296-299

9. Kubbutat MHG, Jones SN and Vousden KH (1997) Regulation of p53 stability by Mdm2. Nature 387: 299-303

10. Sloviter RS, Sollas AL, Dean E and Neubort S (1993a) Adrenalectomy-induced granule cell degeneration in the rat hippocampal dentate gyrus: characterization of an in vivo model of controlled neuronal death. J. Comp. Neurol. 330: 324-336

11. Sloviter RS, Dean E and Neubort S (1993b) Electron microscopic analysis of adrenalectomy-induced hippocampal granule cell degeneration in the rat: Apoptosis in the adult central nervous system. J. Comp. Neurol. 330: 337-351

12. Brady HJ and Gil-Gomez G (1999) The cell cycle and apoptosis. Results Probl. Cell Differ. 23: $127-144$

13. Freeman RS (1998) The cell cycle in neuronal death. In: CellDeath and Diseases of the Nervous System, Koliatsos VE and Ratan RR (eds). Totowa NJ: Humana Press Inc. pp. 103-119

14. Schreiber SS, Sakhi S, Dugich-Djordjevic MM and Nichols NR (1994) Tumor suppressor p53 induction and DNA damage in hippocampal granule cells after adrenalectomy. Exp. Neurol. 130: 368-376

15. Jordan J, Galindo MF, Prehn JH, Weichselbaum RR, Beckett M, Ghadge GD Roos RP, Leiden JM and Miller RJ (1997) p53 expression induces apoptosis in hippocampal pyramidal neuron cultures. J. Neurosci. 17: 1397-1405

16. Xiang $\mathrm{H}$, Hochman DW, Saya $\mathrm{H}$, Fujiwara T, Schwartzkroin PA and Morrison RS (1996) Evidence for p53-mediated modulation of neuronal viability. J. Neurosci. 16: $6753-6765$

17. Sakhi S, Gilmore W, Tran ND and Schreiber SS (1996) p53-deficient mice are protected against adrenalectomy-induced apoptosis. NeuroReport 8: 233-235

18. Honda R, TanakaH and Yasuda H(1997) Oncoprotein MMD2 is a ubiquitin ligase E3 for tumor suppressor p53. FEBS Lett. 420: 25-27
19. Shieh S-Y, Ikeda M, Taya $Y$ and Prives C (1997) DNA damage-induced phosphorylation of p53 alleviates inhibition by MDM2. Cell 91: 325-334

20. Chen J, Wu X, Lin J and Levine AJ (1996) Mdm-2 inhibits the G1 arrest and apoptosis functions of the p53 tumor suppressor protein. Mol. Cell. Biol. 16: $2445-2452$

21. Haupt Y,Barak Y and Oren M (1996) Cell-type specific inhibition of p53-mediated apoptosis by mdm2. EMBO J. 15: 1596-1606

22. Lopes UG, Erhardt P, Yao R and Cooper GM (1997) p53-dependent induction of apoptosis by proteasome inhibitors. J. Biol. Chem. 272: 12893-12896

23. Sakhi S, Sun N, Wing LL, Mehta $P$ and Schreiber SS (1996) Nuclear accumulation of p53 protein following kainic acid-induced seizures. NeuroReport 7: $493-496$

24. Liu W, Rong Y, Baudry M and Schreiber SS (1999) Status epilepticus induces p53 sequence-specific DNA binding in mature ratbrain. Mol. Brain Res. 63: 248 253

25. Ciechanover $A(1998)$ The ubiquitin-proteasome pathway: on protein death and cell life. EMBO J. 17: 7151-7160

26. Alves-Rodrigues A, Gregori L and Figueiredo-Pereira ME (1998) Ubiquitin, cellular inclusions and their role in neurodegeneration. Trends Neurosci. 21: $516-520$

27. Ide T, Takada K, Qiu JH, Saito N, Kawahara N, Asai A and Kirino T (1999) Ubiquitin stress response in postischemic hippocampal neurons under nontolerant and tolerant conditions. J. Cereb. Blood Flow Metab. 19: 750-756

28. Morimoto T, Ide T, Ihara Y, Tamura A and Kirino T (1996) Transient ischemia depletes free ubiquitin in gerbil hippocampal CA1 neurons. Am. J. Pathol. 148: $249-257$

29. Magnusson $\mathrm{K}$ and Wieloch $\mathrm{T}$ (1989) Impairment of protein ubiquitination may cause delayed neuronal death. Neurosci. Lett. 96: 264-270

30. McGahan L, Hakim AM and Robertson GS (1998) Hippocampal Myc and p53 expression following transient global ischemia. Mol. Brain Res. 56: 133-145

31. Di Leonardo A, Linke SP, Clarkin Kand Wahl GM (1994) DNA damage triggers a prolonged p53-dependent G1 arrest and long-term induction of Cip1 in normal human fibroblasts. Genes Dev. 8: 2540-2551

32. Keleti J, Quezado MM, Abaza MM, Raffeld M and Tsokos M (1996) The MDM2 oncoprotein is overexpressed in rhabdomyosarcoma cell lines and stabilizes wild-type p53 protein. Am. J. Pathol. 49: 143-151

33. Saji S, Nakashima S, Hayashi S, Toi M, Saji S and Nozawa Y (1999) Overexpression of MDM2 in MCF-7 promotes both growth advantage and p53 accumulation in response to estradiol. Jpn. J. Cancer Res. 90: 210-218

34. Shkedy D, Gonen H, Bercovich B and Ciechanover A (1994) Complete reconstitution of conjugation and subsequent degradation of the tumor suppressor protein p53 by purified components of the ubiquitin proteolytic system. FEBS Lett. 348: 126-130 